\title{
ALGUMAS CONSIDERAÇÕES SOBRE O CANDOMBLÉ DA BAHIA
}

SOME CONSIDERATIONS ABOUT THE CANDOMBLÉ OF BAHIA

Clara Flaksman

Pós-doutoranda no Programa de Pós-graduação em Antropologia Social do Museu Nacional, Universidade Federal do Rio de Janeiro (PPGAS/MN/UFRJ). 


\section{RESUMO}

Neste artigo apresento parte dos materiais etnográficos relativos à utilização do termo "enredo" no candomblé, especialmente no terreiro Ilê Iyá Omim Axé Iyamassê, mais conhecido como Gantois, em Salvador, capital do estado da Bahia. ${ }^{1}$ Meu objetivo é mostrar como a utilização desse termo revela um princípio ontológico fundamental do candomblé de Salvador que tive a chance de conhecer: o fato de que o contraste entre os verbos ter e ser, nessa religião, não reflete uma oposição como no pensamento ocidental.

Palavras-chave: religiões afro-brasileiras; candomblé; enredo; rede.

\section{ABSTRACT}

In this article I introduce part of the ethnographic material related to the use of the word "enredo" in the candomblé of Salvador, more specifically in the Candomblé temple named Ilê Iyá Omim Axé Iyamassê, currently known as Gantois, where I did my fieldwork. My main objective is to show how the use of this word unveils a fundamental ontological principle of the candomble of Salvador that I had the chance to know: the fact that the contrast between the verbs have and be, in this religion, doesn't reflect an opposition as in the western modes of thought.

Keywords: afrobrazilian religions; candomblé; enredo; network.

${ }^{1}$ Este artigo é uma versão revista da apresentação realizada no âmbito do Programa de Pós-graduação em Ciências Sociais da Pontifícia Universidade Católica (PPGCIS/PUC-Rio), em 2016. Retomo também alguns dos temas já tratados nos artigos "Relações e narrativas: o enredo no candomblé da Bahia" (2016) e "Enredo de santo e sincretismos no candomblé de Salvador, Bahia" (2017). 


\section{Introdução}

O objetivo deste artigo é apresentar uma pequena reflexão sobre a utilização do termo "enredo" no candomblé de Salvador, mais especificamente no terreiro Ilê Iyá Omim Axé Iyamassê, mais conhecido como Gantois. O termo é usado principalmente para se referir às relações místicas que existem na vida das pessoas, relações que podem ser tanto humanas quanto não humanas, como será visto a seguir.

Antes, uma breve explicação sobre a etimologia do termo: "rede" está na origem de "enredar", por sua vez é de onde vem "enredo". Primeiro é o ato ou o efeito de enredar, ou enredar-se: cair na rede, tecer uma rede, organizar uma rede. Segundo, desenvolve-se em paralelo uma gama de sentidos positivos: trama, argumento, sucessão de episódios; e outra, de conotação negativa: mistério, segredo, intriga, captura - por analogia à presa capturada pela teia de aranha, por exemplo. O substrato comum aos dois significados é a transformação do fio em rede, ou do efeito de quem se vê preso (enredado) nessa trama ou teia. Assim, o fio da narrativa vai se combinando, através de uma série de laços ou nós, num enredo, urdindose a trama de um tecido mais complexo.

Autilização do termo "enredo" pelas pessoas do candomblé de Salvador segue muitos sentidos da palavra; porém, em vez de significar somente um deles a cada vez, o termo tem múltiplos significados ao mesmo tempo, podendo assim dar conta dessa relação que é, por si, múltipla.

Passemos, então, aos casos que inspiraram essa reflexão.

\section{Enredo de santo}

Durante toda a minha pesquisa de campo escutei inúmeras vezes a pergunta: "por que você está aqui?". Em quase todo terreiro de candomblé aonde eu ia, alguém me apresentava essa mesma questão.

O mais notável não era a repetição da pergunta, e sim a contínua reiteração do comentário feito a minha resposta, que também se repetia. "Não sei", dizia eu, com uma sinceridade que considerava desconcertante. "Mas eu sei", replicava meu(minha) interlocutor(a). "Você tem enredo."

Claro que o motivo da escolha de determinado tema de pesquisa é uma questão difícil de ser respondida de maneira sintética, como muitos leitores devem saber. Mas, nesse caso específico, é evidente que a pergunta tinha um sentido subliminar. Aos poucos, pude entender como o termo "enredo" representa uma questão fundamental para aqueles que me faziam a pergunta: o fato de eu ter enredo significava que eu teria um motivo válido para estar ali, independentemente da minha simples vontade ou do acaso. 
No candomblé, o acaso não existe. Qualquer pessoa que conheça o funcionamento de um terreiro de candomblé reconhece a limitação da agência humana nesse espaço. Dentro de um terreiro, ou de uma Casa de candomblé, como se diz na Bahia, a vontade principal não é a dos seres humanos, e sim a dos orixás (e do Deus Supremo, Olodumare). Mas enquanto Olodumare permanece inatingível, os orixás se enredam com os seres humanos.

Enredar, nesse caso, significa não somente envolver-se numa trama, numa história, num roteiro. Ter enredo é ter uma relação, ou melhor, um complexo de relações. A utilização mais frequente do termo diz respeito aos laços familiares, que por sua vez também podem ser múltiplos e diversos. Ou seja, quando alguém me dizia que eu tinha enredo, estava querendo dizer, em última instância, que eu tinha uma relação familiar, ancestral - fosse direta ou indireta - com algum orixá; e seria então pela vontade deste que eu estaria ali naquele momento.

Essa relação pode se dar de inúmeras maneiras e em diferentes planos - pois um enredo pode dizer respeito tanto a relações entre orixás quanto a relações entre seres humanos e ainda, com frequência, entre seres humanos e orixás. Essas relações acontecem em planos de existência diversos - o que, no caso dos orixás, tanto tem a ver com os orixás "gerais", as entidades propriamente ditas (Oxum, Iemanjá etc.), quanto com os orixás "individuais", que devem sua existência, salvo raras exceções, à feitura de algum(a) filho(a) de santo.

No plano geral, as relações entre os orixás perpassam toda a sua mitologia. No plano individual, cada orixá feito (o que se chama de "o santo" da pessoa) pode ter diversos tipos de relação com outros orixás, com outras pessoas e mesmo com outras entidades não humanas. Um enredo entre dois orixás individuais, por exemplo, pode fazer com que os seus "filhos" sejam feitos no mesmo barco. Nesse caso, a iniciação concretiza uma relação (ou um enredo) que, na verdade, já existiria desde antes.

As relações entre humanos e orixás também se dão tanto no plano geral (entre uma pessoa e um determinado orixá) quanto no plano individual (entre uma pessoa e um orixá individual, seja seu ou de outrem). Uma pessoa pode, por exemplo, ter enredo com Oxalá e por isso não suportar azeite de dendê. Mas pode também ter algum enredo com um Oxalá determinado, de alguém da sua família, por exemplo, o que geralmente demandaria algum tipo de ação mais específica.

Indaguei a várias pessoas do candomblé sobre o significado do termo "enredo". As respostas foram variadas: "é uma história"; "é a história da vida de uma pessoa"; "é uma coisa de família"; "é uma ligação que você tenha"; e assim por diante. "Enredo é uma palavra bem do candomblé", me disse Mãe Carmen (a mãe de santo do Gantois), quando lhe pedi para definir o seu significado. "Quer dizer a história da pessoa... Mas também quer dizer as coisas 
todas dela, da família dela... Quer dizer um monte de coisa, e todo mundo tem um monte de enredos, cada um diferente do outro."

Então era isso o que me diziam: que eu devo ter enredo com algum orixá; ou então que eu devo ter algum ancestral que por sua vez tinha enredo com algum orixá; ou mesmo que eu devo ter algum parente que tem algum problema não resolvido com alguma entidade, e agora cabe a mim, de alguma maneira, cuidar dessa relação.

"Ninguém chega aqui por acaso", me disseram diversas vezes. "Se você veio parar aqui, é porque aqui é a sua Casa."

Isso condiz com o que me disse certa vez um amigo de Salvador: "a gente sempre acaba na Casa da nossa família. Se você roda, roda e acaba numa Casa jeje, é porque a sua família, lá nos primórdios, vem do Daomé. A gente sabe que o ser humano veio da África. Então todo mundo só está achando o caminho de volta para casa" (informação verbal). ${ }^{2}$ Achar o caminho de volta para casa significa, em última instância, reconhecer o parentesco que há entre a pessoa e o orixá. Sendo o Orixá um ancestral divinizado, como me explicaram inúmeras vezes, intrinsecamente ligado à terra onde viveu quando humano, a volta para casa, representada aqui como uma Casa de candomblé da nação à qual pertence o local, simboliza esse reencontro, essa reconstrução dos laços de parentesco há muito desfeitos.

Voltando, então, para a origem, a escolha do termo é acurada: obedece a critérios etimológicos, abarcando de uma vez todas as possibilidades de significação - e nas veredas de seus possíveis significados pode-se começar a entender o que é (ou tudo que é) um enredo para o candomblé de Salvador. E para entender o enredo, é necessário pensar antes nesse modelo de existência, ou nessa noção de pessoa, ${ }^{3}$ que admite uma multiplicidade de significados. Na seção a seguir, apresentarei as particularidades do terreiro do Gantois que inspiraram esta análise do termo.

\section{Enredo de sangue}

O Gantois é um dos terreiros mais antigos de Salvador. Foi fundado em I849 por Maria Julia da Conceição Nazaré, egressa do Candomblé da Barroquinha, que atende hoje pelo nome de Casa Branca. Desde a sua fundação, o Gantois sempre foi uma casa "familiar": só mulheres da linhagem de sangue da fundadora podem assumir a liderança.

\footnotetext{
${ }^{2}$ Notícia fornecida por Marê, filho de santo de um terreiro do Rio de Janeiro, que conheci durante a pesquisa de campo em Salvador.

3 "Noção de pessoa" é um termo que foi cunhado primeiramente por Marcel Mauss (1950), que mostrou como esse conceito pode variar de acordo com o tipo de sociedade em que se vive.
} 
Além disso, o Gantois tem uma característica marcante: ao longo de toda a sua existência, a maioria de seus filhos de santo (incluindo ogãs e equedes) sempre foi de certo número limitado de famílias. Parte dos membros dessas famílias acabou se concentrando na pequena comunidade que se formou em volta do terreiro, dando origem a uma espécie de compound. No começo, os mais antigos se mudaram para estar perto de sua mãe de santo, já que as obrigações, na época, eram mais longas e mais demandantes. Mas essas casas foram se multiplicando e crescendo para abrigar os descendentes dessas famílias, e hoje há mais de 60 casas de filhos de santo no entorno do terreiro, sejam lajes construídas por cima de antigas casas, ou outras casinhas que foram sendo feitas no entorno das originais.

Todas essas famílias, que descendem basicamente de seis antigas egbomis do terreiro, têm, atualmente, diversos membros feitos no Gantois. Foi traçando essas linhagens familiares que percebi que há certo padrão de distribuição de orixás dentro das famílias: por exemplo, diz-se que todas as mulheres de Ogum têm filhos de Xangô e netos de Ogum. Uma moça de Xangô me contou que sempre soube que teria uma filha de Iansã - "o enredo desses dois é forte!", ela me disse certa vez. O enredo dos orixás, nesse caso, determina o enredo de mãe e filha.

No Brasil, acostumamo-nos a pensar na família de santo, em sua origem, como uma substituta natural da família de sangue: os escravizados, separados à força de seus parentes consanguíneos e agrupados de maneira que os mantinha apartados daqueles com quem conservavam laços genealógicos de solidariedade, em seus clãs ou tribos, trataram de reconstruir simbolicamente seus laços de parentesco. Segundo me explicou um pai de santo de Sergipe que conheci:

\begin{abstract}
A composição das famílias de santo era uma maneira de os escravizados recriarem as estruturas familiares que haviam sido rompidas com a escravidão. O candomblé é uma criação - no seio da Igreja Católica, uma vez que isso era necessário na época, do contrário era proibido - que permitiu aos negros escravizados recriarem a sua família de sangue. As famílias eram sempre separadas, ainda lá na África ou aqui, na chegada: se eles viam que os escravizados eram da mesma família, mandavam um para o Maranhão e o outro lá para o fim do mundo. Os negros escravizados criavam uma nova família através do candomblé. (informação verbal). ${ }^{4}$
\end{abstract}

Toda a estrutura do que conhecemos como candomblé (inclusive o termo) é brasileira. $\mathrm{Na}$ África, cada orixá era cultuado majoritariamente em um determinado lugar por um

\footnotetext{
${ }^{4}$ Notícia fornecida por Pai Ogum Toripê, pai de santo de Aracaju (SE).
} 
sacerdote (ou sacerdotisa) especializado em seu culto. Em Oyó, cultuava-se Xangô, e lá todas as famílias têm Xangô. Assim, todos os que nasciam em Oyó eram considerados, literalmente, descendentes de Xangô. Os que viviam à margem do rio Osun, de Oxum, e assim por diante. Os orixás eram transmitidos, na maioria dos casos, por linhagem paterna, geração após geração. Não havia, portanto, na maioria dos casos, a necessidade de se jogar os búzios para saber qual era o orixá da pessoa (o jogo de búzios tal como o conhecemos hoje quase não existia; a divinação era feita pelo babalaô através do ifá). O orixá era, de fato, um antepassado a que seu "filho" se achava ligado por laços de sangue.

A escravidão mudou esse regime e instaurou novas maneiras de existir para essas religiões tradicionais. Separados à força de suas famílias de sangue, ou seja, de seus orixás, os africanos mandados para o Brasil tiveram que reorganizar as bases de sua religião; "secretar a sua própria concha", nas belas palavras de Bastide (1972). Aqui, separados de seus familiares, e muitas vezes de todos os seus parentes consanguíneos, inventaram um novo modelo organizacional: agruparam todos os orixás na mesma Casa, assentando juntos orixás de diferentes regiões, esquecendo uns e favorecendo outros. Dos mais de quatrocentos orixás que se supõe que existissem na África pré-diáspora, são cultuados no Brasil cerca de dezesseis, com algumas variações. Orixás de origem jeje, como Omolu, Nanã e Oxumarê, passaram a dividir o espaço com orixás dos iorubás, formando, eles também, uma grande família.

Além disso, se na África, originalmente, cada família cultuava um orixá, no Brasil, essa transmissão passou a acontecer de outras maneiras. Em primeiro lugar, o papel das mulheres na religião transformou-se radicalmente: a gradual substituição da adivinhação pelo ifá para a leitura do odu (o destino pessoal) através do jogo de búzios permitiu que as mulheres, de coadjuvantes (uma vez que os adivinhos eram sempre homens, os babalaôs, e a transmissão dos orixás acontecia, como já mencionamos, por linhagem paterna), passassem a ser protagonistas, mães de santo responsáveis tanto pela divinação quanto pela feitura dos orixás. Se em Cuba, por exemplo, o papel dos babalaôs continuou sendo o da divinação, complementado pelas mães de santo que cumprem os rituais e fazem os trabalhos, no Brasil, é a mesma pessoa, seja mulher ou homem (mãe de santo ou pai de santo), que responde tanto pela divinação quanto pelos trabalhos e pelas feituras.

Se na África, portanto, a família de santo e a família de sangue eram a mesma, já que os orixás pertenciam a uma linhagem, sendo transmitidos, na maior parte dos casos, por descendência patrilinear, no Brasil, com a escravidão e a consequente separação das linhagens (que quando conseguiam se manter unidas no navio negreiro eram separadas à força pelos mercadores, já no seu destino, a fim de enfraquecer a organização dos escravizados), a estruturação das famílias passou por uma reformulação. Acostumamo-nos 
a pensar que, assim como os orixás advindos de diferentes regiões passaram a se agrupar sob um mesmo teto, de maneira semelhante ocorreu com aqueles que os carregavam. Morando juntos, sob a égide da escravidão, não lhes restava opção a não ser criarem novas formas de parentesco, a "família simbólica" que viria a se transformar numa característica tão distinta das religiões de matriz africana.

Essa família simbólica seria criada na feitura, tendo como principal núcleo o "barco de iaôs". De cada barco, nascem os "irmãos de barco", categoria de parentesco ainda mais próxima que os "irmãos de santo". Feitos pela mesma mãe e pelas mesmas "mães criadeiras", os "irmãos de barco" compartilham diversas outras características.

Alguns autores defendem que a origem do termo "barco" seria uma referência aos porões dos navios negreiros, onde, deitados lado a lado (como no sabaji, nome dado no Gantois ao aposento onde os noviços ficam recolhidos durante a iniciação), criaram-se os fundamentos básicos para essa nova família, a família de santo. É no sabaji que nasce o novo membro da família: se a feitura é um renascimento, o noviço sai do sabaji pertencendo a uma nova organização parental, a do terreiro: agora ele tem uma nova mãe, a mãe de santo; novos irmãos, os irmãos de santo; e ainda os irmãos de barco, que nasceram junto com ele, espécie de gêmeos místicos com quem dividiram o útero materno, do qual saíram no mesmo momento.

Essa estrutura fez com que muitos autores defendessem que a família de santo é uma nova família, que vem somar-se à família consanguínea daquele que se inicia. Vivaldo da Costa Lima (1977 [2003]), por exemplo, em seu clássico livro A família de santo nos candomblés jeje-nagô da Bahia, descreve a "família-de-santo" como sendo excludente à família de sangue. A pessoa que faz o santo, segundo ele, ganha uma nova família, destacada da sua família consanguínea (embora semelhante a esta em seu funcionamento). Sua análise se norteia, principalmente, pelos princípios de interdição sexual que existem numa Casa de candomblé.

Creio que a questão, no Gantois, possa ser vista de outra maneira. Tomemos como exemplo o caso de Leila, neta de sangue de Mãe Carmen, a atual mãe de santo do Gantois, portanto bisneta de Mãe Menininha. Leila leva consigo, como herança familiar, a Oxum de sua bisavó. Não somente isso: além de Oxum, ela tem na sua cabeça Ewá - a mesma que, ao que tudo indica, também pertencia à Mãe Menininha. Os orixás individuais de Mãe Menininha, nesse caso, passaram diretamente para Leila, sua bisneta, que os recebeu como herança. Nesse caso, linhagem de sangue e de santo se tornaram uma só, e não duas superpostas, como indicou Costa Lima (1977 [2003]). Como entender, pois, a transmissão por herança? O que exatamente é transmitido? Com o modelo da família de santo extensiva à família de sangue, criou-se um modelo de parentesco ontogenético, no qual o santo - ou, em última instância, o axé - se transmite pelo sangue. Verifica-se uma preocupação constante 
com a reconstrução desses laços de parentesco, marcada principalmente pela busca de uma linhagem que seja concomitante, tanto de santo quanto de sangue.

Outro caso é o de Laís, uma iaô recente: a avó era mãe de santo, de Oxum. Quando Laís foi recolhida para fazer o santo, conforme a própria Mãe Carmen me relatou, "todos os santos que estavam na casa da avó queriam a cabeça dela. Foi dificílimo saber qual era a certa! A Oxum da avó tentou de todo jeito entrar na frente das outras, mas a Iansã dela não deixou" (informação verbal). ${ }^{5}$ Quando comentei isso com um amigo local, ele afirmou: "Que enredo, hein, minha filha...". O enredo, no caso, é o conceito que pode dar conta desse parentesco ontogenético em que o santo (ou o axé) se transmite pelo sangue, pelo qual a família de santo e a família de sangue podem estar imbricadas, e não contíguas - e de maneira nenhuma excludentes.

Dona Cici, uma griô (contadora de histórias) de Salvador, certa vez me falou, quando conversávamos sobre esse assunto: "A genética deles está ali dentro. Se você quiser falar de DNA, essas coisas, aí são os brancos que vão explicar, porque os negros explicam desse jeito" (informação verbal). ${ }^{6}$

Comecei este artigo chamando atenção para o fato de que, em Salvador, fala-se o tempo todo que são as relações familiares (ou seja, consanguíneas) que levam alguém a fazer parte do candomblé. Como já apontei, o termo "enredo" descreve essa relação em que a transmissão pelo sangue tem um papel fundamental, pois ter enredo é ser um pouco aquilo com que se relaciona, participar da natureza do outro, ter correndo nas veias tanto o sangue quanto as relações e as histórias que compõem a pessoa no candomblé. E é sobre essa pessoa específica que vou falar na próxima seção.

\section{Noção de pessoa}

$\mathrm{Na}$ literatura sobre a noção de pessoa no candomblé, é recorrente o uso do modelo arquetipal, para o qual os orixás corresponderiam na verdade a arquétipos de personalidade humana, moldes aos quais a pessoa deve sua forma e se limita. A identificação de cada indivíduo com um orixá aplacaria os conflitos internos da própria personalidade, que assim se encaixaria num modelo preexistente representado ao limite nos rituais de possessão. Marcio Goldman (1984) inovou a discussão argumentando que os orixás, em vez de modelos de personalidade, são, eles mesmos, parte da pessoa.

\footnotetext{
${ }^{5}$ Notícia fornecida por Mãe Carmen, mãe de santo do terreiro do Gantois.

${ }^{6}$ Notícia fornecida por Dona Cici, famosa griô de Salvador, que trabalha na Fundação Pierre Verger.
} 
Segundo ele, a pessoa no candomblé é formada ao longo de sua feitura, de acordo com as entidades que vão sendo incorporadas à sua cabeça. No terreiro de nação angola estudado por Goldman, trata-se de sete orixás, mais um erê, um egum e um exu. No Gantois, essa composição não é tão rígida, mas o processo de formação da pessoa é exatamente o mesmo. A cada obrigação (de um, três, sete, quatorze e vinte e um anos), acrescenta-se mais algum componente à pessoa - embora a manipulação da cabeça possa ser levada a cabo a qualquer momento, e há casos em que não se acrescentam novas entidades, mas apenas algo relativo àquelas já assentadas na feitura.

Voltemos ao caso de Leila, a neta da mãe de santo do Gantois. Ela assentou (ou seja, criou um duplo concreto para) a sua Oxum (que vinha da sua bisavó) ainda criança. Alguns anos depois, começou a "passar mal" (como se diz no Gantois quando há o início de possessão pelo santo ainda bruto) algumas vezes, nas festas. Logo Mãe Carmen viu nos búzios que a sua Oxum queria ser feita. Leila, então, se submeteu à feitura. Alguns anos depois, na véspera da sua obrigação de três anos, ela começou a sentir a presença ocasional de outro orixá querendo tomar sua cabeça. "Sua Oxum está estranha", disse-lhe uma de suas irmãs de barco. "Ela nunca foi brava assim, de repente fica andando por aí parecendo que vai bater em alguém!" (informação verbal). ${ }^{7}$ Leila pediu à Mãe Carmen que jogasse os búzios, o que revelou a existência de "um enredo complicado", como ela me falou, ${ }^{8}$ com Ewá (que, como descobriram depois, também vinha de Mãe Menininha). Assim, quando Leila se recolheu para sua obrigação de três anos, assentou Ewá e, a partir daí, em alguns momentos é Ewá quem chega. "Vamos ver quem é que vai aparecer para a minha obrigação de sete anos", ela me disse, brincando. Essa brincadeira, porém, evoca uma importante reflexão sobre a concepção de pessoa corrente no candomblé. Cada história, relação ou enredo tem sempre o potencial de lhe acrescentar um novo elemento - que pode ou não demandar uma representação física. Isso não significa que a pessoa estava incompleta: como já vimos, dependendo do ponto de vista, no candomblé, a pessoa, que é fluida, está sempre completa ou sempre incompleta. Ao contrário do que pode parecer, no entanto, o ritual de iniciação não resulta em duas individualidades indiferenciadas, a do filho de santo e a de seu orixá. Muito pelo contrário, a feitura, concretizando as relações entre o santo e seu filho/sua filha, é o cimento que permite a criação do amálgama pessoa-orixá. Como já mencionei, toda feitura é acompanhada de um assentamento; ao mesmo tempo, no caso de um adoxu, a cabeça é preparada para que o santo chegue, através de um furo aberto em seu couro cabeludo (a catulagem). A conexão entre a cabeça do noviço e o assentamento que representa o seu orixá é estabelecida quando ambos

${ }^{7}$ Notícia fornecida por uma filha de santo do Gantois, feita no mesmo barco de Leila.

${ }^{8}$ Notícia fornecida por Leila. 
são banhados com o mesmo sangue. Na criação desse duplo cabeça/assentamento, constituise um enredo que adquire uma expressão concreta.

Penso que podemos somar o argumento de Goldman (de que a pessoa é o conjunto de suas entidades) a uma ideia que Bastide (1958 [2000]) apresenta em seu livro O candomblé da Bahia, segundo a qual a pessoa é composta de suas histórias. Nas múltiplas instâncias dessa junção, o conceito de enredo adquire importância e frequência no candomblé. A formação da pessoa se dá na soma das histórias envolvendo seres humanos e não humanos - os enredos que compõem a sua vida.

Acompanhei também o caso de um rapaz que estava prestes a fazer o santo em um terreiro cuja mãe de santo é filha de santo do Gantois. Ele estava pronto para fazer Ogum e assentar Oxalá, os dois orixás que a mãe de santo havia visto em sua cabeça. Entretanto, logo antes de iniciar seu recolhimento, a mãe de santo lhe perguntou se alguma coisa diferente vinha acontecendo em sua vida nos últimos meses. Então ele lhe contou que, havia algum tempo, um passarinho que piava em sua janela o acordava todo dia pontualmente às cinco da manhã, assim que o sol começava a aparecer. Ele tentou várias técnicas para apanhar o passarinho, ou espantá-lo, e nada funcionou. A mãe de santo ouviu em silêncio e, ao fim da história, deu o diagnóstico: ele tinha enredo com Oxóssi. Jogou os búzios, que confirmaram o que ela havia concluído. Assim, durante a iniciação do noviço, Ogum foi feito, e tanto Oxalá quanto Oxóssi foram assentados. Com isso, o passarinho nunca mais piou em sua janela. $\mathrm{O}$ enredo definiu o assentamento, o duplo de sua cabeça, para que Oxóssi pudesse ser cuidado como queria e não precisasse mais lhe mandar nenhum emissário.

No candomblé, a pessoa está sempre se fazendo, sendo construída. Cada novo elemento que surge - ou seja, cada novo enredo - acopla-se aos demais, formando uma totalidade momentânea. Cada enredo é, a um tempo, todo (por ser completo em si) e parte (pois cada um é sempre parte de um enredo maior, que por sua vez nunca se completa). Ou seja, a própria composição da pessoa se faz de acordo com o seu enredo. É a relação com os orixás que faz com que eles apareçam e muitas vezes precisem de um assentamento para serem cuidados da maneira adequada.

Sabe-se que os assentamentos de orixás, no candomblé, devem necessariamente ter uma pedra, ao redor da qual somam-se outros elementos que variam de acordo com o orixá a ser assentado. Mas a pedra sempre está presente: ela serve de morada ao orixá ao mesmo tempo que é o orixá. A um só tempo, o orixá tanto está na pedra quanto é a própria pedra, assim como é a conta e está na conta, é uma parte da cabeça de seu filho e mora na cabeça de seu filho. Não se trata de metonímia: a parte não representa o todo, ela é o todo - são indiscerníveis. Iroko, por exemplo, é orixá e árvore: a árvore sagrada que existe em todo terreiro (gameleira) é o Iroko da Casa. Perguntei a vários filhos de santo sobre a relação entre 
a árvore e o orixá: "a árvore é a morada do orixá"; "a árvore é o orixá"; "a árvore representa o orixá". Mas não é qualquer pé de gameleira que é um Iroko; para isso, é necessário preparar a árvore, alimentá-la, vesti-la.

Da mesma maneira, ter enredo equivale também, até certo ponto, a ser um pouco a coisa, a entidade ou a pessoa com quem cada um se relaciona. Esse é um fundamento básico da cosmologia das religiões de matriz africana: um tipo de relação em que o ser e o estar não estão separados. Assim, uma pessoa que tem enredo com Oxum é em parte Oxum, ou uma parte de Oxum; uma Oxum que tenha enredo com Oxóssi é em parte Oxóssi, e assim por diante. Ter enredo é dispor de uma relação de parentesco, é carregar consigo um pouco do outro. A individuação, no candomblé, não pressupõe uma relação entre a parte e o todo. O todo transcende a parte, explica a parte: as partes se submetem ao todo, e por ele são definidas.

O modelo de pessoa coerente com todos os aspectos do candomblé é o da pessoaconjunto: e o melhor termo a se usar para descrever essa concepção múltipla de pessoa, esse modelo de ser e de estar no mundo, seria, ainda aqui, "enredo" - descrição que, com seus múltiplos significados, pode dar conta de uma relação em que, como já explicado, ser e estar se confundem, em que ter algo é, em certa medida, ser parte de algo. Ou seja, a pessoa não é uma totalidade, mas uma totalização - nunca se completa, embora esteja completa a cada instante. Dependendo do ponto de vista, no candomblé, a pessoa, que é fluida, está sempre completa ou sempre incompleta.

Fenômeno semelhante se passa entre os orixás. Pode-se pensar que o panteão dos orixás se organizaria à maneira das cores no espectro do arco-íris. Sabe-se que o arco-íris é um fenômeno óptico que surge pelo desdobramento da luz do sol, originalmente branca (composta pelo conjunto de todas as cores), em um espectro sucessivo de cores. Isso acontece quando a luz do sol sofre refração e reflexão nas gotas de chuva. As sete cores que nós (ou pelo menos a maioria de nós) conseguimos diferenciar são apenas as que se pode distinguir a olho $\mathrm{nu}$; mas o espectro da luz do sol é contínuo, ou seja, na verdade o arco-íris exibe um infinito de cores. Entre uma cor e outra, portanto, sempre se encontram mais algumas. Entre o verde e o amarelo existe um "verde amarelado"; entre o "verde amarelado" e o amarelo, um "verde ainda mais amarelado"; e assim por diante. Nessa visão mais rica e complexa da escala cromática, a separação não é perfeitamente delimitada e não existe divisão nítida: cada faixa invade a área da seguinte, mesclando-se a ela, como dois conjuntos em interseção.

Entre Oxum e Iansã, portanto, haveria Oxum Apará, uma Oxum que tem enredo com Iansã. Entre Iemanjá e Ogum, há Iemanjá Ogunté, uma Iemanjá que tem enredo com Ogum. Mas, como vimos, todos os orixás mantêm relação - ou enredo - uns com os outros. Relação que pode manifestar-se como oposição. Certo dia, uma filha de santo do Gantois com quem 
eu conversava fez o seguinte comentário: "Gente de Oxalá é maluca, porque Oxalá está muito perto de Exu". Perguntei a ela como se dá essa proximidade, e ela me explicou:

No xirê, por exemplo, Exu é o primeiro, Oxalá é o último. E é uma roda, 360 graus, então o primeiro e o último se encontram. Eles são opostos, já que gente de Oxalá veste branco e não pode nunca nem usar as cores de Exu, mas ainda assim estão próximos. É que nem Xangô e Omolu. Eles são opostos também, mas estão do lado um do outro. E está cheio de gente de Xangô que tem enredo com Omolu. Eles são como dois lados de uma moeda. E o que está mais próximo de um lado da moeda que o outro lado dela? (informação verbal). ${ }^{9}$

A proximidade entre Oxalá e Exu, nesse caso, significa que Oxalá é um pouco Exu. E o mesmo se dá entre Xangô e Omolu. E a relação entre os orixás, no caso, não se limitaria à proximidade, mas, como ocorre com as cores do arco-íris, produziria um espaço comum, uma área de interseção. Assim como ocorre com as pessoas, entre os orixás a totalidade nunca está necessariamente contida, não existe em suas relações uma delimitação clara das fronteiras. Algo sempre pode passar para o outro, infiltrando-se por esses limites de definição incompleta, o que faz com que o termo "enredo" também possa ser usado no sentido de emaranhamento, de como o candomblé funciona, por vezes, como uma teia em que a pessoa se enreda e não consegue mais se soltar. Aproximar-se, em muitos momentos, é enredar-se. Nesse sentido, pode-se pensar no candomblé como uma "máquina de captura", com os terreiros exercendo uma força centrípeta destinada à captura do axé.

Outro filho de santo do Gantois, que também é pai de santo de um terreiro, me falou que os nossos termos, na Língua Portuguesa, são insuficientes para descrever as relações do candomblé. Ele se referia às relações familiares entre os orixás, e usou como exemplo o fato de que um orixá pode ser, ao mesmo tempo, mãe e mulher de outro, e que isso não é uma incongruência. "A gente que não tem uma palavra que defina isso em Português", disse-me ele.

O único jeito seria mesmo criar uma linguagem toda nova. Como a gente não tem, fica aí quebrando a cabeça para explicar umas coisas que na verdade são tão simples... Se bem que são complexas ao mesmo tempo, se é que você me entende. Porque a gente tem mania de separar as coisas, mas no candomblé o que há é indistinção: o orixá, por exemplo, está dentro e fora da gente, e isso é a mesma coisa. Você entende? O candomblé é um mundo, e para se mergulhar nele, o que vai acontecer é que você vai, vai, vai e não vai chegar a lugar nenhum. Então são coisas que às vezes a gente tem que

${ }^{9}$ Notícia fornecida por uma filha de santo do Gantois. 
tentar entender mesmo na superficialidade. Porque se for mergulhar demais, acaba se afogando.(informação verbal). ${ }^{10}$

\section{Referências}

BASTIDE, R. As religiões africanas no Brasil. São Paulo: Edusp, I97 I. vols. I e 2.

BASTIDE, R. Estudos afro-brasileiros. São Paulo: Perspectiva, 1972.

BASTIDE, R. Estudos afro-brasileiros. São Paulo: Perspectiva, I983.

BASTIDE, R. Le principe d'individuation. Contribuition à une philosophie africaine. In: COLLOQUE INTERNATIONAL DU CNRS: LA NOTION DE PERSONNE EN AFRIQUE NOIRE. Paris: L'Harmattan, 1973. p. 33-43.

BASTIDE, R. O candomblé da Bahia: rito nagô. São Paulo: Companhia das Letras, I958 [2000]. COSTA LIMA, V. da. A familia de santo nos candomblés jeje-nagôs da Bahia: um estudo de relações intragrupais. Salvador: Corrupio, 1977 [2003].

ELBEIN, J. Os nàgô e a morte: pàde, àsèsè e o culto égun na Bahia. Petrópolis: Vozes, I975 [2012].

FLAKSMAN, C. Narrativas, relações e emaranhados: os enredos do candomblé no terreiro do Gantois, Salvador, Bahia. 20I4. Tese (Doutorado em Antropologia Social) - Universidade Federal do Rio de Janeiro, Rio de Janeiro, 2014.

FLAKSMAN, C. Enredo de santo e sincretismos no candomblé de Salvador, Bahia.R@U,v. 9, n. 2, p. 153-169, 2017.

FLAKSMAN, C. Relações e narrativas: o enredo no candomblé da Bahia. Religião e Sociedade, v. 36, n. I, p. I3-33, 2016.

GOLDMAN, M. A possessão e a construção ritual da pessoa no candomblé. 1984. Dissertação (Mestrado em Antropologia Social) - Universidade Federal do Rio de Janeiro, Rio de Janeiro, 1984.

GOLDMAN, M. Formas do saber e modos do ser: observações sobre multiplicidade e ontologia no candomblé. Religião e sociedade: Instituto de Estudos da Religião, Rio de Janeiro, v. 25, n. 2, p. IO2-I2O, 2005.

GOLDMAN, M. O dom e a iniciação revisitados: o dado e o feito em religiões de matriz africana no Brasil. Mana: Estudos de Antropologia Social. Rio de Janeiro: Contra Capa, 20I2. p. 269-288.

\footnotetext{
${ }^{10}$ Notícia fornecida por um filho de santo do Gantois.
} 
HALLOY, A. Dans l'intimité des orixás: corps, rituel et apprentissage religieux dans une famillede-saint de Recife (Brésil). 2005. Tese (Doutorado em Ciências Sociais) - Université Libre de Bruxelles, Bruxelles; École des Hautes Études en Sciences Sociales, Paris, 2005.

HALLOY, A. «Chez nous, le sang règne!» L'apprentissage religieux dans le culte xangô de Recife. Terrain 55, p. 40-53, 2010.

MAUSS, M. Uma categoria do espírito humano: a noção de pessoa, a de "eu". Sociologia e Antropologia. São Paulo: Cosac Naify, I950 [2003]. p. 369-400.

SEGATO, R. L. Santos e daimones: o politeísmo afro-brasileiro e a tradição arquetipal. Brasília: Editora UnB, 1995 [2005].

VERGER, P. F. Notion de personne et lignée familiale chez les yoruba. In: COLLOQUE INTERNATIONAL DU CNRS: LA NOTION DE PERSONNE EN AFRIQUE NOIRE. Paris: L'Harmattan, I973. p.6I-7I.

VERGER, P. F. Fluxo e refluxo: do tráfico de escravos entre o Golfo do Benin e a Bahia de Todos os Santos dos séculos XVII a XIX. São Paulo: Corrupio, I987.

VERGER, P. F. Notas sobre o culto aos orixás e voduns. São Paulo: Edusp, I999 [2012].

VERGER, P. F. Orixás. Salvador: Corrupio, 2002. 